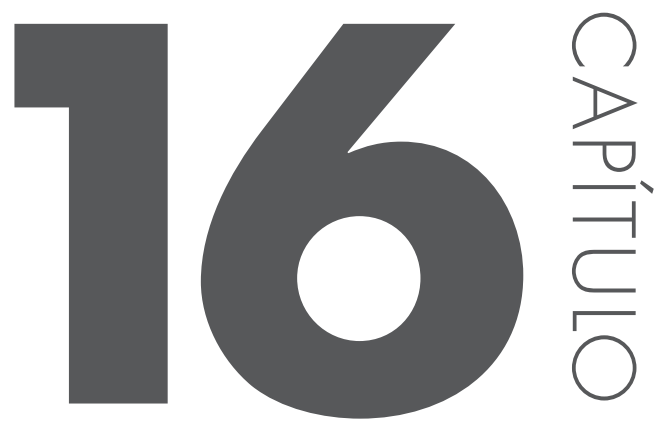

\title{
AGRICULTURA FAMILIAR E IDENTIDADE TERRITORIAL: a comunidade rural Olhos D'água no município de Catalão (GO)
}

NAVES, Laila ${ }^{1 *}$; MENDES, Estevane de Paula Pontes ${ }^{2}$

' Geógrafa pela Universidade Federal de Goiás, Regional Catalão. Núcleo de Estudos e Pesquisas Socioambientais (NEPSA/CNPq)

2 Geógrafa, Professora da Universidade Federal de Goiás, Regional Catalão. Núcleo de Estudos e Pesquisas Socioambientais (NEPSA/CNPq)

*email: laila.snaves@gmail.com

\section{RESUMO}

$\mathrm{Na}$ agricultura familiar os produtores são proprietários dos meios de produção e assume o trabalho no estabelecimento produtivo e ainda possuem um sentimento de pertencimento com a propriedade onde vivem, trabalham, tem sua religiosidade. $\mathrm{O}$ presente estudo tem por objetivo compreender as principais discussões sobre a agricultura familiar e a identidade cultural, ressaltando o comportamento sociocultural, econômico e organizacional da comunidade Olhos D’água no município de Catalão (GO). Para efetivação da pesquisa foi realizada uma revisão da literatura sobre a temática agricultura familiar e identidade territorial. A pesquisa empírica foi realizada em dez de 
2010, sendo aplicado um total de 10 roteiros de entrevistas. Apesar da sucessão do patrimônio sociocultural estar ameaçado devido à migração dos filhos dos pequenos produtores para a cidade em busca de melhores condições de vida a sua identidade não esta ameaçada, pois, a raiz dos filhos dos produtores está no campo. Assim, os filhos que moram na cidade auxiliam os pais na limpeza dos pastos, além de visitarem os pais sempre que necessário, e ainda participam dos terços e das festas na comunidade.

Palavras-chave: Agricultura familiar; Identidade territorial; Comunidade Olhos D'água, Catalão (GO)

NAVES, Laila; MENDES, Estevane de Paula Pontes; "AGRICULTURA FAMILIAR E IDENTIDADE TERRITORIAL: a comunidade rural Olhos D'água no município de Catalão (G0)", p. 256-274 . In: Seminário de Pesquisa, PósGraduação e Inovação da Regional Catalão (2. : 2014 : Goiás) Coletânea Interdisciplinar em Pesquisa, PósGraduação e Inovação - Volume 1 : Estudos Ambientais, Território e Movimentos Sociais. Anais [livro eletrônico] / organizado por Adriana Freitas Neves, Idelvone Mendes Ferreira, Maria Helena de Paula, Petrus Henrique Ribeiro dos Anjos. São Paulo: Blucher, 2015. ISBN: 978-85-8039-109-1, DOI 10.5151/9788580391091-V1_Cap16 


\section{INTRODUC̣ÃO}

$\mathrm{Na}$ agricultura familiar os produtores são proprietários dos meios de produção e assume o trabalho no estabelecimento produtivo e ainda possuem um sentimento de pertencimento com a propriedade onde vivem, trabalham e têm sua religiosidade. Salienta-se que os agricultores familiares têm a sua identidade cultural fundamentadas nas tradições, religiosidade e nos costumes. Comumente os antepassados dos agricultores familiares viveram no mesmo lugar carregado de simbologia e de significados.

As discussões a cerca da agricultura familiar tiveram maior enfoque a partir da década de 1990. Com a modernização da agricultura em curso agravaram as condições de inserção no mercado e de reprodução do agricultor familiar, sendo assim, através da ampliação do setor mercantil de alimentos não seria viável investir em pequenas propriedades, pois, os incentivos em créditos foram direcionados para as grandes propriedades.

Os agricultores familiares do município de Catalão (GO) vivem no lugar onde estabelecem suas relações de trabalho, suas relações de poder e sua religiosidade que são uma das dimensões construtoras de identidade. A ênfase do estudo assenta-se no fato da agricultura familiar no Brasil apresenta diversidade e diferenciações regionais, o que torna relevante as pesquisas e as análises de áreas específicas para a compreensão da organização e reprodução desse segmento. É importante ressaltar que os agricultores familiares possuem uma identidade cultural, fundamentadas nos valores, tradições, religiosidade, festividade, vizinhança e parentesco. Nesse contexto, propõe-se compreender as principais discussões sobre a agricultura familiar e a identidade cultural, ressaltando o comportamento sociocultural, econômico e organizacional da comunidade Olhos D'água no município de Catalão (GO).

Para a efetivação da pesquisa foi realizada uma revisão de literatura, utilizando obras que discutem as temáticas: agricultura familiar, identidade e cultura. Foram analisados os aspectos teóricos e os dados empíricos de trabalhos que exploram a realidade dos produtores familiares do município de Catalão (GO). A pesquisa empírica foi realizada na comunidade Olhos d'água, no município de Catalão (GO), em 2010. Foi aplicados um total de 10 roteiros de entrevista. Esta comunidade dista aproximadamente $60 \mathrm{~km}$ da Sede do Município e $11 \mathrm{~km}$ do Distrito de Santo Antônio do Rio Verde. É importante destacar que a principal via de acesso á essa Comunidade é a BR-050 até o Distrito de Pires Belo, e seguindo pela GO-506 e que a referida Comunidade conta hoje com cerca de 15 sedes residenciais. 


\section{DEFINIÇÕES E CARACTERÍSTICAS DO TERMO AGRICULTURA FAMILIAR NA CONTEMPORANEIDADE E OS ASPECTOS FORMADORES DAS IDENTIDADES}

A agricultura familiar caracteriza-se através da relação entre terra, trabalho e família. O trabalho dos agricultores familiares é realizado pela família e quando necessário é contratado os trabalhadores temporários. Os agricultores familiares caracterizam pelas relações de solidariedade entre os parentes, amigos e vizinhos.

Com base nisso, a unidade de produção familiar pode ser compreendida através de uma forte relação entre terra trabalho e família. Cada família é detentora da terra, dos instrumentos de trabalho e de um conjunto de técnicas para a administração do patrimônio, que pode ser passado de geração a geração. A força de trabalho empregada na terra é geralmente composta pelos próprios membros das famílias e, de acordo com a necessidade, por trabalhadores temporários (LAMARCHE, 1993).

Nessa perspectiva, a definição da agricultura familiar segundo Abramovay (1992) ressalta três traços básicos: a) os membros estão relacionados por parentesco ou casamento; b) a propriedade dos negócios é usualmente combinada com controle gerencial; e, c) o controle é transmitido de uma geração para outra dentro da mesma família. Desse modo, a agricultura familiar possui relações fundadas nos laços de parentesco e de vizinhança. $\mathrm{O}$ autor analisou que as relações de parentesco ou mesmo a solidariedade dos vizinhos demonstra que os produtores ajudam uns aos outros. É importante destacar que esse tipo de relação está desprovida de qualquer lógica capitalista, isto é, o produtor que recebeu o auxílio retribui em outra oportunidade o serviço prestado.

De acordo com Mendes (2005), as principais características das unidades familiares de produção rural são: a) centralização dos meios de produção; b) os proprietários asseguram diretamente a gestão e o trabalho; c) é dada ênfase na diversificação da produção de gêneros alimentícios e na multiplicidade de atividades; d) a produção é voltada tanto para o autoconsumo quanto para o mercado consumidor; e) há uma valorização dos recursos naturais e culturais; f) o trabalho assalariado complementar é utilizado somente quando necessário; g) associação de rendimentos agrícolas e não agrícolas; h) as estratégias de reprodução são imediatamente subordinadas às condições externas de mercado; i) a área total é menor ou igual a quatro módulos fiscais de terra, que são quantificados de acordo com a legislação em vigor, ou no máximo seis módulos, quando se trata de pecuária familiar.

Com o processo de modernização do campo os agricultores familiares 
tiveram dificuldades de inserir-se aos mercados e isso agravou a situação do pequeno produtor tanto no aspecto econômico quanto organizacional, visto que, a modernização do campo trouxe consigo modificações no próprio núcleo familiar. Entretanto, o agricultor familiar tem criado estratégias que o possibilita permanecer no campo e dele tirar seu sustento. As estratégias familiares são um conjunto de técnicas que o pequeno produtor utiliza para se manter no campo. Para Brumer et al. (1993),

[...] as estratégias familiares são respostas dadas por cada família a fim de assegurar ao mesmo tempo a sua própria reprodução e a de sua exploração. Poder-se-ia dizer, simplificando, que o grande desafio dos agricultores brasileiros consiste em garantir um espaço aos numerosos 'herdeiros', um lugar de trabalho (muitas vezes a própria exploração familiar), sem que isso se torne técnica e economicamente inviável. (BRUMER et al. 1993, p. 205, grifo do autor).

Corroborando com o autor as estratégias podem ser definidas como um conjunto de ações racionais, em que cada membro da família tem à necessidade de assegurar, ao mesmo tempo, a própria reprodução e a do grupo, tendo sempre a consciência dos mecanismos que podem proporcionar tais objetivos, como a tradição, e a vinculação ao processo moderno de viver e produzir (LAMARCHE 1998; PERTINARI 2007).

A reprodução do modo de vida dessas famílias está ligada às estratégias por elas adotadas. Essas estratégias familiares consistem em assegurar que as novas gerações consigam se manter no campo (BRUMER et al. 1993). Para estes autores, cada família busca estratégias para garantir sua própria sobrevivência no campo e enfrentar o desafio de dar a seus herdeiros um local de trabalho na propriedade, de maneira que esse seja economicamente viável.

Cabe analisar, que a principal estratégia adotada pelos agricultores familiares é a diversificação das atividades, assim eles comercializam produtos, e utilizam para o consumo familiar. Parte do princípio, que o trabalho realizado pelos agricultores familiares é um conjunto de técnicas de trabalho que os pequenos produtores aprenderam com seus pais e avós para permanecerem no território onde constituem suas identidades territoriais.

Dessa forma, o patrimônio sociocultural, ou seja, as técnicas de trabalho e produção passadas de geração em geração, estão vinculadas à construção das identidades dos produtores rurais, e a constituição delas é influenciada pelas instituições produtivas e reprodutivas, pela memória coletiva e por fantasias 
pessoais, pelos aparatos de poder e revelações de cunho religioso (CASTELLS, 2008).

A formação das identidades está relacionada com a vivência dos indivíduos que trabalham com a terra e que possuem crenças, costumes e religiosidade. $\mathrm{O}$ conceito de identidade também está vinculado às relações subjetivas dos indivíduos e dos grupos que possuem sentimento de pertencimento com o lugar de vivência. Os aspectos que formam as identidades dos indivíduos estão ligados aos sentimentos que eles sentem pelo lugar de refúgio, e como também, pelos objetos presentes nos lugares de memória.

Os indivíduos possuem sensações e emoções ao relacionar uns com outros, pois, vivem juntos e trabalham juntos, analisa-se que a construção das identidades também está vinculada à tradições, à religiosidade, e aos símbolos. É importante elencar que o conceito de identidade é estabelecido relacionalmente e contrastivamente.

Cherlotti e Pessôa (2010) abordam que a identidade é construída por subjetividades individuais e coletivas e pode estar relacionada a grupos sociais ou ao pertencimento territorial, na qual a incorporação da dimensão simbólica, do imaterial no discurso geográfico, tem possibilitado as análises sobre a produção do espaço, das paisagens e territorialidades.

Analisa-se que a construção das identidades está ligada ao conceito de subjetividade que permite uma exploração dos sentimentos que estão envolvidos no processo de produção da identidade e do investimento pessoal que fazemos em posições específicas de identidade (WOODWARD, 2009).

Nessa linha de análise, a construção da identidade também está relacionada à vivência, ao lugar onde os indivíduos se refugiam à religiosidade. Isto é, ela é carregada de caráteres subjetivos e objetivos.

Desse modo, o conceito de identidade está vinculado à existência de um indivíduo, bem como, o reconhecimento mútuo entre eles e a solidariedade interna do grupo. Os atores sociais partilham o mesmo lugar onde são perpetuadas as memórias coletivas das identidades no espaço simbólico. Salienta-se que

[...] a construção de uma identidade passa pela consideração de uma herança e pela preservação de um patrimônio sócio-histórico, e se a capacidade de recordar, preservar e perpetuar um passado faz parte de um sentimento identitário, este último encontra um local de expressão privilegiada nos "lugares de memória” (LÉ BOSSÉ, 2004, p. 168, grifo do autor). 
Portanto os lugares de memória são carregados de símbolos e de subjetividades. O território identitário passa a ser considerado como o local de práticas ativas e atuais, por intermédio dos quais se vivenciam as identidades, e não somente um ritual simbólico. As práticas literárias e artísticas, as paisagens, passam a fazer parte integrante de uma territorialidade simbólica através da qual, os grupos afirmam e reivindicam sua identidade política e cultural em relação com seu próprio lugar (LÉ BOSSÉ, 2004). O lugar é sede das identidades, onde os indivíduos conversam, partilham das mesmas crenças, possuem sentimento de pertencimento com o local de vivência.

\section{AS TRADIÇÕES CULTURAIS E RELIGIOSAS: A COMUNIDADE OLHOS D'ÁGUA NO MUNICÍPIO DE CATALÃO (GO)}

A Comunidade possui indivíduos que se identificam uns com os outros. De acordo com Park (1973) um indivíduo só é membro de uma comunidade na medida em que participa da vida comum. Esse autor vai avançar em relação aos conceitos anteriores ao observar as interações comunicativas mediadas por dispositivos simbólicos, como a linguagem. Assim, os aspectos simbólicos (valores, costumes e identidades) aparecem como fator relevante na compreensão de comunidade. Pondera-se que quando os indivíduos vivem em comunidade e possui uma relação com a natureza e com a terra, e com a religião, eles partilham as mesmas ideias, participam das festas, rezam juntos, constituem suas identidades coletivas.

Os produtores rurais da comunidade Olhos D'água possuem um forte laço de pertencimento com o local onde vivem. Nessa perspectiva, Tedesco (1999, p. 88, grifo do autor) afirma que "[...] a comunidade sempre funcionou como uma reciprocidade social, familiar e de vida religiosa, 'um lugar de encontro', uma forma de compensação aos desencontros, isolamentos, sofrimentos e individuações cotidianas.”

O Senhor P. C. da. Silva (informação verbal, Catalão (GO), dez. 2010) não soube dizer com exatidão quando surgiu a comunidade Olhos D'água, o que faz acreditar que a mesma surgiu antes de 1900, mesmo período que ocorreu o aparecimento de outras comunidades no município de Catalão (GO). As primeiras famílias pioneiras chegaram às demais comunidades da região no fim do século XIX, cuja migração foi favorecida pela construção da rede ferroviária. 
O nome da comunidade Olhos D'água originou-se devido antigamente chover muito, e minava água em vários pontos da área, os ditos “olhos d'águas". A Comunidade é formada por pequenos produtores, que apresentam mão de obra predominantemente familiar. Suas atividades econômicas são voltadas para produção leiteira. Possuem uma forte ligação com a religiosidade, com o território onde vivem, possuem laços de parentesco, amizade e solidariedade com os vizinhos.

As relações de amizade e vizinhança das famílias antigas é um traço marcante na Comunidade Olhos D’água. A origem das famílias mais antigas e tradicionais da região que o Sr. P. C. da Silva (informação verbal, Catalão (GO), dez. 2010) se recordam eram as de Candido, Silva, João Lopes e Fernando Safatle. O tamanho das famílias variava entre nove e treze filhos. O casal que tivesse um filho era porque a mulher tinha algum problema ou o casal morria cedo. Nessa época os partos eram realizados por parteiras que moravam na região.

Nesse sentido, o fato das famílias rurais mais antigas serem numerosas refletia no tamanho das residências. As habitações rurais eram geralmente grandes, com janelas de madeira, o que permitia uma boa ventilação, o piso era de chão batido. Os estabelecimentos eram divididos em sala, (copa geralmente eram ligadas aos quartos) e, varanda na saída da sala. A cozinha era bem espaçosa para receber as visitas, sendo que algumas residências apresentavam paiol, que serviam de depósito para carnes de porco em conserva na manteiga ou para carnes de sol salgadas que eram guardadas em caixotes protegidos com palhas secas de milho ou de bananeira. Essas casas eram construídas com tijolos de adobe e com madeira (palhas secas produzidos com barro misturados com capim picado). Nessa época a iluminação das casas era feita por candeia de ferro ou a lamparina que era usada pelas famílias mais ricas (MENDES, 2005).

A educação era mais rigorosa apreendiam desde cedo as tarefas domésticas. A divisão do trabalho se dava da seguinte forma: os pais geralmente cuidavam do gado, do plantio e do cultivo. Já as mães cuidavam das atividades domésticas e outros serviços, como fabricação da farinha e do polvilho, manutenção da hortaliça. Algumas mulheres ajudavam os homens. Outro papel importante das mães era o de costurar para família, elas faziam as roupas de cama, lençóis, cobertas de algodão.

Antigamente os filhos começavam a ajudar os pais com oito a dez anos de idade, as filhas auxiliavam as mães, na busca de água nos córregos ajudavam descaroçando o algodão, apreendiam a costurar. Já os filhos apreendiam a tirar leite, apartar as vacas, na limpeza de pasto. Sobre o assunto, Andrade (2008) coloca que o trabalho das crianças servia como ferramenta na construção de 
costumes ligados aos significados do trabalho no modo de vida rural, isto é, como pressuposto da formação cultural de pessoas honestas, dignas e de boa índole.

Um fato relevante na comunidade Olhos D'água é que não havia agregados. Segundo Sr. P. C. da Silva (informação verbal, Catalão/GO, dez. 2010) quem trabalhava na propriedade era só a família, responsável pelos serviços da propriedade. Ele coloca que, como os vizinhos são unidos quando havia muito serviço eles faziam o mutirão.

Na região, a prática de troca de dia de serviço é muito comum. Esse tipo de serviço ocorre quando o produtor necessita ir há cidade, assim, ele pedia seu vizinho para apartar as vacas. Nessa perspectiva, os produtores rurais da comunidade Olhos D'água possuem laços de amizade e solidariedade. Sobre o assunto Candido (1979) coloca que a "troca de serviço" se dá quando um vizinho é requisitado para auxiliar o outro, e fica seu devedor de uma parcela de tempo igual a que recebeu, podendo requerer quando julgar conveniente, pois o cômputo de semelhante serviço se faz rigorosamente, como se fosse dívida monetária.

Há práticas de realizações de mutirões com menos intensidade que ainda ocorrem geralmente aos sábados. Essa atividade ocorre quando o proprietário geralmente encontra-se com serviço atrasado e convida os amigos, parentes e vizinhos para auxiliá-lo na limpeza de rego d'água construção de cerca, para plantar arroz, na colheita, para abater pasto, e no final do dia o proprietário fazia uma festa com música e dança, A esposa preparava um café da manhã reforçado e, posteriormente, fazia o almoço, e servia o lanche à tarde. O último mutirão que ocorreu na Comunidade foi em 2009. Foi realizado pela Associação dos Pequenos Produtores da comunidade Olhos D'água (APROAGRI) e reuniu cerca de 15 pessoas. A APROAGRI quer continuar a realizar o mutirão porque é uma atividade que auxilia todos os produtores da comunidade Olhos d'Água.

$\mathrm{Na}$ comunidade Olhos d'água o mutirão era realizado por 50 a 60 famílias de produtoras chegando em média a 100 pessoas. Havia também o mutirão das mulheres onde reuniam de 10 a 30 mulheres denominadas fiandeiras e as tecedeiras para fiar isto é, fazer os fios de algodão e, posteriormente, reuniamse novamente para tecer o tecido de algodão. As fiandeiras cantavam músicas típicas do mutirão. A Sra. D. M. da. S. (informação verbal, Catalão/GO, dez. 2010) recordou de alguns versos da música: "[...] fia, fia, fia, minha rodinha vamo acabá com esse algodão para poupar essa preguiça de quem tá fazendo mutirão [...]"

Ela aborda que as mulheres ficavam 'bravas' devido o conteúdo da música, mas era muito divertido elas bebiam pinga, conversavam, relembravam o 
passado. Quando sua mãe era viva ela tinha vontade de continuar a realizar o mutirão das fiandeiras mais a quantidade das mulheres que sabiam fiar na comunidade reduziu significativamente, pois as fiandeiras eram mais idosas e com o tempo elas faleceram e as sucessoras, ou seja, suas filhas não tiveram interesse de continuar a tradição, estas achavam mais fácil comprar a coberta pronta na cidade. Assim, a chegada do capitalismo no campo facilitou o fim da tradição das fiandeiras na comunidade Olhos D’Água.

Nesse sentido, o mutirão associa o trabalho coletivo e a solidariedade dos produtores rurais ligado também ao serviço e a festa, afetividade com os vizinhos. Corroborando com autor, Candido (1998) afirma que

[...] o mutirão não é propriamente um socorro, um ato de salvação ou um movimento piedoso; é antes um gesto de amizade, um motivo para folgança, uma forma sedutora de cooperação para executar rapidamente um trabalho agrícola. (CANDIDO, 1998, p. 69).

Há também a traição, que era realizada de surpresa por amigos, parentes e vizinhos quando o produtor não tinham condições para fazer a convocação para executar a surpresa. Esta atividade é diferenciada do mutirão devido à primeira ocorrer quando o produtor está sobrecarregado de serviço ou por motivo de doença. Os amigos percebendo que o produtor necessita de ajuda faz a surpresa, a sua esposa geralmente fica sabendo com antecedência. Assim, prepara os biscoitos, o almoço (MENDES, 2005). De acordo com Candido (1998, p. 69) “[...] traição é uma terminologia regional utilizada para significar o caráter de surpresa da demão/mutirão.” Percebe-se que na traição o beneficiário dos serviços não efetuava o convite, ele era surpreendido.

Para Mendes (2005), o mutirão e a traição ocorrem com bem menos frequência atualmente. Segundo Martins Silva (2008), embora essas práticas já tenham sido comuns na comunidade Cruzeiro dos Martírios, contando com a participação de cerca de 20 a 30 pessoas, hoje a traição e o mutirão inexistem nessa comunidade. Entretanto, elas ainda são praticadas, mas com pouca expressão, nas Comunidades Olhos D’água, Mata Preta, Morro Agudo/ Cisterna, Ribeirão, Custódia e São Domingos no município de Catalão (GO) (VENÂNCIO, 2008).

Nas Comunidades Olhos D’água e São Domingos, segundo Venâncio (2008), foi constatado que a traição, em tempos passados chegava a reunir até 100 pessoas, hoje, nas raras vezes que ela é praticada, limita-se à participação de 10 e 15 pessoas. Na comunidade Olhos D’água o mutirão também chegava 
reunir até 100 pessoas, atualmente quando ocorre há participação de15 a 20 pessoas.

Nesse contexto, os aspectos culturais dos produtores rurais da comunidade Olhos D'água em Catalão (GO) são estudados com base em fatores, como as relações familiares e as formas de trabalho. Destacam-se nessa comunidade as tradições religiosas, os laços de amizade e de vizinhança. Andrade (2008), ao pesquisar aspectos da religiosidade na Comunidade Rural Tenda do Moreno, no município de Uberlândia (MG), diz que a análise da maneira como a religiosidade influencia o cotidiano dos moradores do meio rural é de grande importância, visto que eles estabelecem uma espécie de código de conduta, permeados pela idéia da obrigação para com a religião. A religiosidade e a solidariedade dos moradores da comunidade Olhos D'água são características relevantes, pois, são duas dimensões construtoras das identidades. Elas são construídas através das relações de solidariedade e de união nos terços, nas festas. Portanto o lugar de vivência é carregado de elementos materiais/objetivos e imateriais/subjetivos que contribuem para constituição identitária dos indivíduos.

Essa influência da religião no modo de vida do produtor familiar é também observada nas comunidades rurais Coqueiro, Mata Preta, Ribeirão, Morro Agudo/Cisterna, Olhos D'água do município de Catalão (GO), onde as festas de roça estão entre as mais conhecidas manifestações culturais e de religiosidade (MENDES, 2008). De maneira geral, as festas são consideradas como uma forma de romper com a rotina, após muito tempo de trabalho. Essas festividades constituem também um elemento de sociabilidade entre as famílias e vizinhos e, conforme afirma Candido (1999), são os meios usados pelos produtores para agradecer aos santos pela fartura alcançada no ano.

Para Martins Silva (2011) as Festas são expressões religiosas importantes para os moradores das Comunidades. As festas religiosas, como fenômeno cultural, têm sido redescobertas e revitalizadas como um campo fértil de investigação histórica, transcendendo sua visibilidade e revelando crenças e vivências demarcadas por um tempo e uma identidade coletiva. É um momento de celebração da vida, o rompimento do ritmo monótono do cotidiano, o que permite ao sujeito experimentar afetos e emoções. Caracterizam-se como um momento do cotidiano marcado pelas intensidades e complexidades das relações ali expressas através de símbolos e ritos peculiares.

As festas de roça no município de Catalão (GO) são geralmente organizadas pelos próprios moradores. Suas origens costumam estar associadas à devoção de algum morador, que iniciava rezas de terços em louvor a um santo em nome de alguma graça alcançada. Inicialmente, a participação era de poucas pessoas, com o passar do tempo o número de participantes aumentou gradativamente, 
de tal maneira que foi necessário encontrar locais mais apropriados para essa atividade, o que resultou na construção de capelas. As festas de roça constituem, além do caráter religioso, uma manifestação social, uma forma de reunir e rever parentes e amigos das regiões circunvizinhas (MENDES, 2005).

Na comunidade Olhos, D’água a religião predominante é a católica. O terço iniciou através de uma mulher natural do Estado do Paraná que mudou-se para Comunidade em meados da década de 1990. Os Santos Homenageados são: São Sebastião (20 de Janeiro), Nossa Senhora da Abadia (20 agosto) e Nossa Senhora Aparecida (12 de outubro). Através das festas, as famílias tiveram oportunidade de realizarem a reza do terço (Reza típica da religião Católica, que é composto pelas seguintes orações: Credo, Pai-Nosso, Ave-Marias, Glória, $1^{\circ}$ e $2^{\circ}$ Mistérios e Salve Rainha) para os santos e era um momento de diversão e confraternização dos amigos e vizinhos da região.

Na Comunidade Olhos D’água, o Santo mais Festejado é São Sebastião. Assim tanto na referida Comunidade como na Comunidade São Domingos, estudada por Venâncio (2008), sendo São Sebastião o Padroeiro. De acordo com Venâncio (2008), a adoração ao santo é justificada pela sua representatividade na luta contra a peste, a fome e a guerra. Assim, todos os criadores de gado e produtores de alimentos entregam sua produção à proteção de São Sebastião.

Atualmente, na Comunidade Olhos D’água ocorre o terço cantado em Louvor a São Sebastião que, geralmente ocorre no final de semana mais próximo do dia 20 de janeiro, entretanto o dia correto é dia 20 do mesmo mês, devido ser um final de semana mais apropriado para a reza. No início da reza é realizada a procissão próxima ao Centro Comunitário, a qual é carregada de símbolo, como por exemplo, a imagem de São Sebastião, uma cruz, o mastro, isto é uma bandeira com a imagem de São Sebastião. É tradição o preparo de doces de leite, doce de mamão, doce de mamão com leite, doce de figo, doces cristalizados, e café que são servidas após o terço.

No terço em Louvor a São Sebastião, havia dois casais responsáveis pela organização, porém os moradores da Comunidade também auxiliam, na realização do terço. A responsabilidade de organizar o terço é a cada ano feito para outros casais da comunidade. Em 2001, esta reza foi realizada pelo conselho da Igreja Católica, formado por moradores da Comunidade. Assim o lucro da festa passou a ser destinado para a igreja, representada pela Paróquia Mãe de Deus. Na reza de São Sebastião dois casais são escolhidos para a entrega da coroa, eles fazem uma promessa para o Santo, e no outro ano geralmente eles ficam responsáveis de fazer os doces. Outro fator importante culturalmente é a reza do terço em Louvor a São Sebastião que acontece todo último domingo do mês, geralmente o terço é cantado. Nesse contexto, o lugar dos produtores 
rurais da comunidade Olhos d'água é um espaço que contém símbolos notados no terço de São Sebastião, através da qual, as identidades são formadas, e estão abertas a reconstruções.

Os produtores rurais fazem promessas para São Sebastião pedindo proteção para a criação de bovinos, suínos, galináceos e para as plantações de milho. Nesse sentido a promessa é a relação mutua entre os indivíduos e os santos. Cumprindo a promessa, acreditam que o santo fará o mesmo retribuindo-lhe com o beneficio do pedido (MARTINS SILVA, 2012).

$\mathrm{Na}$ Comunidade Olhos D'água ocorre a festa em homenagem a Nossa Senhora da Abadia, que semelhante a comunidade Anta Gorda era realizada por casais e passou a ser realizada pelo conselho. O ciclo de festas de roça ocorre em junho na Comunidade Anta Gorda e em julho na Comunidade Olhos D'água, são homenageados respectivamente os santos São Sebastião e Nossa Senhora da Abadia.

Na Comunidade São Domingos, estudada por Venâncio (2008), a festa em Louvor a Nossa Senhora da Abadia foi extinta desde a década de 1960, pois não encontrou mais pessoas interessadas em fazê-la. Já na comunidade Olhos D'água, a festa tradicional continua sendo executada geralmente no mês de agosto. A festa de São Sebastião já data 130 anos e é realizada anualmente. Essa festa não acontece no dia de São Sebastião (20 de janeiro), varia de maio a agosto, sendo que cada festeiro a prepara conforme a data mais propícia. Para Venâncio (2008) a festa é divida em dois momentos: a partir das 19h, é realizado o terço cantado e a adoração a São Sebastião. A partir das 21h, acontece o momento de lazer, com danças, leilões, alimentação, que se estende pela madrugada toda.

A festa de Nossa Senhora da Abadia data de mais de 60 anos que é feita na Comunidade Olhos D'água. Atualmente recebe em média de 300 a 400 pessoas da cidade de Catalão e dos Distritos de Santo Antônio do Rio Verde e Pires Belo e região circunvizinha. Geralmente são três dias de reza, fé e diversão. Ela inicia geralmente no dia 14 de agosto. A festa é constituída inicialmente pelo terço, posteriormente pelo Forro (uma mistura de músicas caipiras) através da qual é tocada uma sessão de música (30 minutos) e em seguida (20 minutos) de leilão. Desse modo, a presente festa é uma manifestação cultural, onde através da religiosidade e da solidariedade dos produtores rurais, a identidade cultural é preservada.

Outra manifestação cultural é a reza de Todos os Santos, que ocorria na Comunidade Anta Gorda e atualmente é realizada na comunidade Olhos D'água, a mesma acontece para agradecer a chuva e/ou pedir para que chova. Essa reza, geralmente, é feita no dia 1 de novembro, é constituída 
pela reza do terço e, posteriormente, é oferecido quitandas. A reza de todos os Santos foi interrompida durante 30 anos voltou a ser realizada em 1991. Isso ocorreu devido a um período de insuficiente de precipitação enfrentado pela Comunidade, o que levou os moradores voltarem a realizá-la, para pedir mais chuva. A reza de todos os Santos é para os produtores da Comunidade e, geralmente, os moradores da Comunidade Anta Gorda também, assim o número de produtores que participam da festa é em media é 30 a 40 pessoas.

Nesse contexto os produtores da Comunidade Olhos d'água argumentam que a reza em homenagem a Todos os Santos restringem aos moradores da Comunidade, pois, é considerado uma tradição, e um ato de fé, e devoção, aos Santos. Os produtores rurais afirmam que não convidam os moradores da cidade de Catalão (GO) para não perder as raízes da reza de Todos os Santos. Eles buscam nos Santos a solução para as dificuldades do cotidiano, marcando presença na vida dos produtores rurais. Assim, os Santos são vistos como divindade que protegem os produtores e a Comunidade contra os males.

A Festa dos Produtores Rurais é também chamada de "Festa do Peão", sendo realizada pela Associação dos Pequenos Produtores da Comunidade Olhos D'água. Essa festa é realizada desde 2003. Tal manifestação cultural é composta de rodeios, leilões, forró (música caipira), a mesma acontece no final de agosto. A Festa do Peão recebe centenas de pessoas por dia (cerca de 300 a 400), dentre elas recebe indivíduos de Catalão (GO), Santo Antônio do Rio Verde e Pires Belo e região.

Essas festas caracterizam-se como um momento de confraternização entre as comunidades. Os produtores se divertem e ao mesmo tempo, preservam suas tradições, é um momento de procissão, reza, promessa e diversão. Sobre o assunto, Venâncio (2008), coloca que as festas sofreram transformações, mas mesmo assim, os produtores preservam os laços comunitários e a religiosidade.

Outra importante festa é a Novena de São Sebastião. As Comunidades São Domingos e Cruzeiro dos Martírios têm São Sebastião como padroeiro. De acordo com Martins Silva (2008), essa festa é realizada na Comunidade Cruzeiro dos Martírios anualmente, entre os dias 17 e 20 de janeiro, diferentemente do que ocorre na Comunidade São Domingos, onde, conforme Venâncio (2008), não há uma data estabelecida para a sua realização. Atualmente, essa festa recebe centenas de participantes por dia, em 2007 houve uma participação estimada de 400 a 500 pessoas (VENÂNCIO, 2008).

Outra festa muito conhecida na região de Catalão (GO) é a Encomenda das Almas, realizada na Comunidade Mata Preta há mais de cem anos, acontece nos três últimos dias da Semana Santa, entre as 20h e 01h (MENDES, 2008). É vedada a participação de mulheres e crianças, assim como é proibido a qualquer 
morador abrir portas ou janelas para ver o ritual. De acordo com a pesquisa de Mendes (2008), os antigos 'encomendadores' de almas da região da Mata Preta contam que as pessoas que abriam as portas, para ver e/ou acompanhar os rezadores, viam almas vestidas de branco acompanhando a procissão, fazendo com que os curiosos voltassem assustados para suas casas.

Nestas Comunidades do município de Catalão (GO) (Coqueiro, Mata Preta, Ribeirão e Morro Agudo/Cisterna, São Domingos, Cruzeiro dos Martírios e Olhos D’água) são visíveis as relações de parentesco, vizinhança, amizade e compadrio. As relações de parentesco assumem um papel importante na preservação do modo de vida do produtor familiar

Desse modo, a identidade e o pertencimento dos moradores da Comunidade Olhos D'água e das demais Comunidades rurais Coqueiro, Mata Preta, Ribeirão e Morro Agudo/Cisterna, São Domingos e Cruzeiro dos Martírios no município de Catalão (GO) são construídos por manifestações religiosas, laços de vizinhança, de parentesco e de amizade. Mesmo através das transformações ocorridas, as famílias da Comunidade Rural Olhos D’água do município de Catalão (GO) asseguram a reprodução do patrimônio cultural.

\section{CONSIDERAC̣ÕES FINAIS}

A modernização da agricultura favoreceu os grandes empresários, em contrapartida, os pequenos produtores enfrentaram diversas dificuldades dentre elas a falta de investimentos por parte do Estado. Mesmo enfrentando dificuldades os produtores têm criado estratégias produtivas para permanecer no campo e dele tirar o seu sustento. As estratégias é um conjunto de técnicas tradicionais de trabalho e produção que seus antepassados transmitiram para os produtores continuarem no lugar de vivência. Nesse segmento os produtores lançam mão de várias estratégias produtivas. Nesse contexto, as identidades foram construídas através do patrimônio sócio cultural e também a religiosidade é outra dimensão formadora das identidades dos produtores familiares da Comunidade Olhos D’água.

Parte do princípio, que as identidades dos agricultores familiares são formadas nos lugares de memória carregados de símbolos e subjetividades, pois foram nesses lugares que seus antepassados, trabalharam, conversaram e rezaram. As tradições religiosas é uma das características dos produtores rurais da Comunidade Olhos D’água. Nas rezas os agricultores são solidários, isto é uns auxiliam os outros para fazer os doces e biscoitos para 
os terços e as festas. Nesse sentido, as relações de amizade, solidariedade e parentesco prevalecem na Comunidade.

Nas diferentes Comunidades Rurais no município de Catalão (GO) os produtores tem conseguido manter as manifestações religiosas mesmo diante das dificuldades. Na Comunidade Olhos D’água o Terço em Louvor a São Sebastião, a Reza em Louvor a Todos os Santos e a Festa de Nossa Senhora da Abadia, são manifestações religiosas tradicionais, constituída por signos e devoção aos santos e símbolos.

Apesar da sucessão do patrimônio sociocultural estar ameaçado devido à migração dos filhos dos pequenos produtores para a cidade em busca de melhores condições de vida a sua identidade não esta ameaçada, pois, as raízes dos filhos dos produtores estão no campo. Assim, os filhos que moram na cidade auxiliam os pais na limpeza dos pastos, além de visitarem os pais sempre que necessário, e ainda participam dos terços e das festas na Comunidade. 


\section{Title: FAMILY FARMTERRITORIALAND IDENTITY: the rural community Eyeswaterin the municipality of Catalão (GO)}

\section{Abstract}

In the family farm producers own the means of production and takes the job in establishing productive and still have a sense of belonging to the property where they live, work, have their religiosity. This study aims to understand the main discussions on family farming and cultural identity, emphasizing the behavior sociocultural, economic and community organizational Eyes water in the municipality of Catalão (GO). To execute the research was carried out a literature review on the topic family farming and local identity. The empirical research was conducted in Dec 2010, and applied a total of 10interview scripts. Despite. The succession of socio-cultural heritage under threat due to the migration of the sons of small farmers to the city in search of better living conditions to their identity is not threatened, because the roots of the sons of farmers are in the field. Thus, the children who live in the city assist parents in cleaning the pastures, besides visiting parents whenever necessary, and still participate thirds of partie.

Keywords: Family farming. Territorial identity. Community of Olhos D'água, Catalão (GO). 


\section{REFERÊNCIAS}

ABRAMOVAY, R. Paradigmas do capitalismo agrário em questão. São Paulo: Hucitec, 1992. 275 p. (Estudos Rurais, 12).

ALMEIDA, M. G.; CHAVEIRO, E. F.; BRAGA, H. C. (Org.). Geografia e cultura: os lugares da vida e a vida dos lugares. Goiânia: Vieira, 2008.

ASSOCIAÇ̃̃O BRASILEIRA DE NORMAS TÉCNICAS. NBR 6023: informação e documentação: referências: elaboração. Rio de Janeiro, 2002.

BRANDENBURG, A. Colonos: subserviência e Autonomia. In: FERREIRA, A. D. D.; BRANDENBURG, A. (Org.). Para pensar outra agricultura. Curitiba: Editora UFPR, 1998. p. 288.

BRUMER, A. et al. A exploração familiar no Brasil. In: LAMARCHE, H. (Coord.). Agricultura familiar. Tradução Ângela M. M. Tigiwa. Campinas: UNICAMP, 1993. p. 179-234. (Coleção Repertórios).

CANDIDO. A. Os parceiros do Rio Bonito: estudo sobre o caipira paulista e a transformação dos seus meios de vida. 8. ed. São Paulo: Duas Cidades, 1998. 284 p.

CASTELLS, M. 0 poder da identidade. Tradução de Klauss Brandini Gerhardt. 6. ed. São Paulo: Paz e Terra, 2008. (A Era da Informação: Economia, sociedade e cultura, v. 2).

CHELOTTI, M. C.; PESSÔA, V. L. S. Reterritorialização e identidade territorial: os camponeses construindo novas territorialidades na fronteira Brasil/Uruguai. Disponível em: <http:// webcache.googleusercontent.com/custom? q=cache:7bxPynnk3esl:egal2009.easyplanners.info/ area06/6057_Cervo_Chelotti_Marcelo.pdf+tradi\%C3\%A7\%C3\%A30+camponesa\&cd=6\&hl=pt-BR\&ct $=$ clnk\& client=pub-7149744994785345>. Acesso em: 7 abr. 2010.

LAMARCHE, H. (Coord.). Agricultura familiar: comparação internacional. Tradução de Ângela M. N. Tiiiwa. Campinas: Unicamp, 1993. (Coleção Repertórios).

LE BOSSÉ, M. As questões de identidade em geografia cultural - algumas concepções contemporâneas. In: CORREA, R. L.; ROSENDAHL, Z. (Org.). Paisagens, textos e identidade. Rio de Janeiro: EdUERJ, 2004. p. 157-179. (Geografia Cultural).

MARTINS SILVA, J. A agricultura familiar em Goiás: a Comunidade Cruzeiro dos Martírios no município de Catalão. 2008. 83f. Trabalho Final de Curso (Graduação em Geografia) - Campus Catalão, Universidade Federal de Goiás, Catalão, 2008.

MENDES, E. de P. P. A produção rural familiar em Goiás: as comunidades rurais no município de Catalão. 2005. 294f. Tese (Doutorado em Geografia) - Desenvolvimento Regional e Planejamento Ambiental) - Faculdade de Ciências e Tecnologia, Universidade Estadual Paulista, Presidente Prudente, 2005.

TEDESCO, J. C. (Org.). Agricultura familiar: realidades e perspectivas. 3. ed. Passo Fundo: UPF, 2001.

VENÂNCIO, M. Território de esperança: tramas territoriais da agricultura familiar na comunidade rural São Domingos em Catalão (GO). 2008. 178 f. Dissertação (Mestrado em Geografia) - Instituto de Geografia, Universidade Federal de Uberlândia, Uberlândia, 2008. 